\title{
Built environment interventions for human and planetary health: integrating health in climate change adaptation and mitigation
}

\author{
Jason H Prior ${ }^{a, i}$, Irena LC Connon ${ }^{a, h}$, Erica McIntyre ${ }^{b}$, Jon Adams ${ }^{b}$, \\ Anthony Capon ${ }^{c, d}$, Jennifer Kente, Chris Risselc, Leena E Thomas ${ }^{\dagger}$, \\ Susan M Thompson' and Harriet Westcotte
}

a Institute for Sustainable Futures, University of Technology Sydney, NSW, Australia

${ }^{b}$ Faculty of Health, University of Technology Sydney, NSW, Australia

c Sydney Medical School, University of Sydney, NSW, Australia

d Guest Editor, Public Health Research \& Practice, Issue 4, 2018

e Sydney School of Architecture, Design and Planning, University of Sydney, NSW, Australia

\section{Article history}

Publication date: December 2018

Citation: Prior JH, Connon ILC, Mclntyre E, Adams J, Capon A, Kent J, Rissel C, Thomas LE, Thompson SM, Westcott H. Built environment interventions for human and planetary health: integrating health in climate change adaptation and mitigation. Public Health Res Pract. 2018;28(4):e2841831. https://doi.org/10.17061/phrp2841831

\section{Key points}

- Built environment professions have a key role to play in addressing the health effects of human-generated climate change

- Built environment climate change adaptation interventions can contribute to improving human health

- Built environment mitigation interventions address the interconnectedness of human health and planetary health through a 'cobenefits' framework

- Interventions must transition the ethics of the built environment beyond sustainability to improving human and planetary health, but this is not without challenges

\section{Abstract} professionals. f School of Architecture, University of Technology Sydney, NSW, Australia

g Built Environment, UNSW Sydney, Australia

h School of Social Science, University of Dundee, Scotland, United Kingdom

Corresponding author: Jason.Prior@uts.edu.au
Objectives: Human-generated climate change is causing adverse health effects through multiple direct pathways (e.g. heatwaves, sea-level rise, storm frequency and intensity) and indirect pathways (e.g. food and water insecurity, social instability). Although the health system has a key role to play in addressing these health effects, so too do those professions tasked with the development of the built environment (urban and regional planners, urban designers, landscapers and architects), through improvements to buildings, streets, neighbourhoods, suburbs and cities. This article reports on the ways in which urban planning and design, and architectural interventions, can address the health effects of climate change; and the scope of climate change adaptation and mitigation approaches being implemented by the built environment professions.

Type of program or service: Built environment adaptations and mitigations and their connections to the ways in which urban planning, urban design and architectural practices are addressing the health effects of climate change.

Methods: Our reflections draw on the findings of a recent review of existing health and planning literature. First, we explore the ways in which 'adaptation' and 'mitigation' relate to the notion of human and planetary health. We then outline the broad scope of adaptation and mitigation interventions being envisioned, and in some instances actioned, by built environment

Results: Analysis of the review's findings reveals that adaptations developed by built environment professions predominantly focus on protecting human health and wellbeing from the effects of climate change. In contrast, built environment mitigations address climate change by embracing a deeper understanding of the co-benefits inherent in the interconnectedness of human 
health and wellbeing and the health of the ecosystem on which it depends. In the final section, we highlight the ethical transition that these approaches demand of built environment professions.

Lessons learnt: Built environment interventions must move beyond simple ecological sustainability to encouraging ways of life that are healthy for both humans and the planet. There are key challenges facing this new approach.

\section{Introduction}

Less than a decade ago, health was recognised as a "serious blind spot" in climate change discussions. ${ }^{1}$ In recent years, a growing field of research and interventions have emerged, driven by the recognition that climate change poses an "unacceptably high and potentially catastrophic risk to ... health", and that "tackling climate change could be the greatest ... health opportunity of the 21 st century". ${ }^{2}$ Although health professionals are fundamental for tackling the health implications of climate change, those professions responsible for the development of the built environment - urban and regional planners, urban designers, landscapers and architects - also have a critical role to play in addressing these challenges. ${ }^{3}$ Indeed, with their focus on design and planning, built environment professionals are in a unique position to influence both the direct pathways (including heatwaves, sea-level rise, extreme weather events and water shortages) and indirect pathways (food and water insecurity, changing patterns of disease, raised levels of pollution, increased social instability and mental ill health) through which climate change affects health.

Historically, built environment professions have had a crucial role in improving physical and mental health. ${ }^{4,5}$ Their recent interest in the development of adaptations and mitigations to address links between climate change and health builds, in part, on their long-standing focus on shaping buildings and cities to mitigate human greenhouse gas ( $\mathrm{GHG}$ ) emissions that contribute to climate change. ${ }^{6}$

In this article, we reflect on the future scope of built environment adaptations and mitigations and their connections to the ways in which urban planning, urban design and architectural practices are addressing the health effects of climate change. Our reflections draw on the findings of a recent review of existing health and planning literature. ${ }^{7}$ This combined systematic and narrative review of existing health and built environment journals was undertaken between January and July 2018 by the authors of this paper. The review was undertaken as part of the Healthy Higher Density Living research project and it examined how human and planetary health have been understood in the planning literature to date. It also looked at how these understandings have shaped the development of existing and envisioned planning strategies that are responsive to health impacts associated with human-generated climate change.
In this article, we first explore the ways in which 'adaptation' and 'mitigation' relate to the notion of human and planetary health. We then outline the broad scope of adaptation and mitigation interventions being envisioned, and in some instances actioned, by built environment professionals according to the existing body of scholarly literature. We also highlight the ethical transition within built environment practices demanded by an increased awareness of the built environment's role in promoting health for humans and the planet, and outline the implementation challenges faced by such developments.

\section{Adaptation, mitigation and health}

Climate change adaptations implemented by built environment professionals focus predominantly on protection of human health from the effects of climate change. In contrast, mitigations address climate change by embracing a deeper understanding of the interconnectedness of human health and wellbeing, and the health of the natural systems on which we all depend (see Figure 1). We define adaptation as managing the unavoidable consequences of climate change, and mitigation as measures that seek to avoid further unmanageable impacts.

Figure 1. How health is conceptualised in built environment climate change adaptation and mitigation

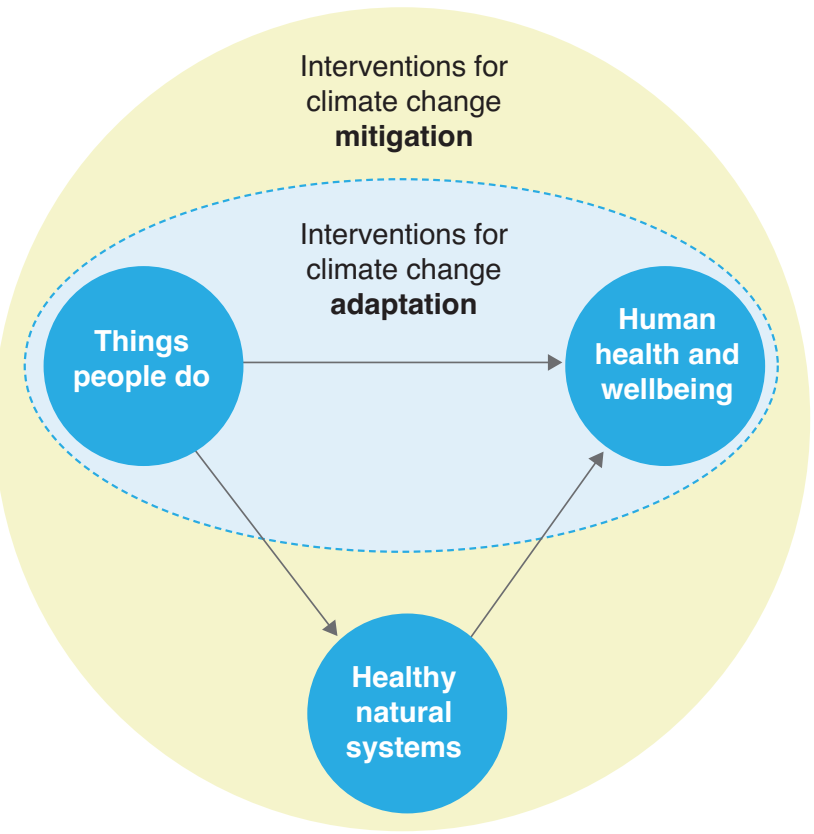


Both adaptation and mitigation approaches are considered necessarily complementary among built environment professionals. Adaptation measures are implemented in response to the immediate consequences of climate change and to help reduce the adverse effects of these on human health and wellbeing. Meanwhile, mitigation measures are understood as fundamentally important to alleviate the longer-term health effects of climate change on the health of humans and natural systems. ${ }^{3}$

Climate change adaptation focuses on adjusting the built environment, and the community's way of life, to reduce climate change threats to human health and wellbeing from adverse effects such as air pollution, the spread of disease vectors, food insecurity and undernutrition, displacement and mental ill health. Examples of built environment adaptation interventions mentioned in the existing literature are shown in Box 1.

Box 1. Examples of built environment adaptation interventions

- Increased greening and blueing (creating more water bodies) in urban spaces and adapting building codes (e.g. better insulation) to reduce heat-related mortality and stress from extreme heat events and urban heat-island effects ${ }^{8}$

- Settlement planning and building codes that use forward-looking climate projections to reduce morbidity and mortality from extreme weather events ${ }^{9}$

- Local air pollution management (e.g. car-free days) to reduce respiratory illnesses amplified by extreme weather and temperature variation ${ }^{10}$

- Land and water pollution management and remediation (e.g. installation of home water filters) to reduce morbidity and mortality from contaminants caused by sea-level rises and temperature changes

- Adapting land-use planning and building codes to changes in vector-borne infectious diseases caused by temperature changes resulting from climate change ${ }^{11}$

- Agricultural planning to reduce malnutrition by moving or changing crop production to promote food security from extreme weather events and temperature variation ${ }^{12}$

- Settlement planning that decreases social unrest through adapting to sea-level rises.

In contrast to the adaptation focus on human health and wellbeing, mitigation is increasingly understood as approaching health through a 'co-benefits' approach: a more systematic understanding of the benefits of mitigation to both natural ecological systems and human health and wellbeing (with a sustainability framework used as a starting point for analysis). ${ }^{13}$ The co-benefits approach recognises that the built environments can promote low-carbon ways of living that benefit the health of the natural environment through the reduction of human-generated GHG emissions. At the same time, applying a co-benefits approach has the potential to generate human health benefits.

Mitigation practices can influence the development of the built environment to reduce the sources of the GHGs that contribute to climate change, or improve the sinks that naturally remove them from the atmosphere. It is increasingly recognised that these GHG mitigation activities benefit both the natural system ${ }^{13,14}$ and human wellbeing. For example, promoting active transport by providing bicycle paths, walking tracks and public transport within urban areas has the potential to reduce $\mathrm{GHG}$ emissions. Also, active transport use has the potential to help improve mental health, human flourishing and happiness, and reduce rates of noncommunicable diseases such as obesity and diabetes which are increasingly associated with sedentary urban lifestyles. ${ }^{15}$ Box 2 presents examples of built environment mitigation interventions, highlighting some of their co-benefits to human and planetary health.

Box 2. Examples of built environment mitigation interventions

- Integrated transport planning that encourages active lifestyles, and public transport that uses less fuel and produces lower carbon dioxide emissions; cobenefits to human health include reduced rates of obesity, diabetes and cardiovascular diseases

- Land-use zoning and urban design that intensifies urban forests and blue spaces within cities to accelerate the removal of GHGs from the atmosphere through increasing carbon dioxide sinks; co-benefits to human health include reduced heat-related mortality and stress, and maintenance of mental health

- Urban design and building codes that reduce energy demands, water use and GHG emissions (e.g. zero net energy developments); co-benefits to human health include reduced morbidity, mortality and stress from heat events and extreme weather events

- Social planning and agricultural planning that promote shifting human diets away from livestock consumption towards plant consumption to mitigate GHG emissions and promote food security; cobenefits to human health include reduced rates of undernutrition and increased social stability

- Promotion of decentralised, renewable and efficient energy generation (e.g. wind energy, direct solar, bioenergy, hydropower) to mitigate GHG emissions and increase stability of power supply; co-benefits to human health include increased social stability and reduced morbidity and mortality from the reduction of the health impacts that stem from the environmental effects associated with increasing GHG emissions/concentrations. 


\section{Embracing a new ethics and confronting the challenges}

An increased consciousness among the built environment professions of the ways in which the built environment shapes climate change and health will give rise to new ethical and practical challenges. These develop from and extend beyond ecological sustainability. Climate change forces built environment professionals to recognise that the extent and trajectory of human health is, ultimately, dependent on flourishing planetary life-support processes. ${ }^{16}$ In addition, climate change provides opportunities for decision makers to question the ethics that underpin and drive practices that maintain unstable relationships with the environment, and to transform existing approaches. ${ }^{17} \mathrm{~A}$ key challenge for built environment professionals is to ensure that adaptation and mitigation practices enable humans to more readily address the effects of climate change. It is also essential that, in delivering their intended objectives, built environment policies and actions do not inadvertently lead to increasing GHG emissions, which in turn could further drive anthropogenic climate change and adverse health effects. This challenge of maladaptation can be overcome if practitioners adopt a proactive and future-orientated approach to improving human health. This requires transitioning from simple, unidimensional adaptation responses based on one-directional, causeand-effect views of the relationship between environment and health, to the deployment of a combination of new adaptation- and mitigation-based approaches that incorporate multidimensional feedback loops between human and environmental health.

Health outcomes provide a powerful driver for the uptake of built environment climate change adaptation and mitigation. Although the link between adaptation and health is more obvious, using a co-benefits approach, where mitigation costs are offset through health budget savings, provides built environment professionals with a powerful argument to encourage government and industry to invest in what can otherwise be perceived as expensive low-carbon living options.

Despite these opportunities, several important challenges to understanding the place of health in built environment adaptation and mitigation remain:

- Planners continue to tend to rely on traditional solutions to climate change that favour highly evident and direct effects on human health ${ }^{3}$

- Designing and planning for climate change differs significantly from traditional urban planning in that a lack of knowledge and experience about the health efficacy of responses hinders decision making ${ }^{18}$

- Collective efforts require local and regional coordination, which can be difficult to achieve, especially as the majority of present interactions between health professionals and built environment professionals remain largely limited to implementing checklists to improve health outcomes rather than taking a long-term collaborative approach ${ }^{19}$

- There is a need for improved decision making support tools to inform planning professionals about how to integrate health outcomes in decision making

- A disconnection between access to data and processing capacity limits can lead to maladaptation

- Increased attention needs to be given to understanding variation in the vulnerability of the health of human populations, and parts of the natural ecosystem, to climate change $\mathrm{e}^{20}$

- Although adaptation and mitigation can occur at multiple scales, further research is required to explore how it can best be undertaken in high-density urban developments.

\section{Conclusion}

Health effects from human-generated climate change present significant challenges for built environment professionals. However, this challenge also presents exciting opportunities for new planning interventions that transition built environment ethics towards improving both human and planetary health. Present interactions between health professionals and built environment professionals remain largely limited to implementing checklists designed to improve health outcomes. This can be in the assessment of development applications or other strategic planning episodes (e.g. New South Wales Government, Healthy Urban Development checklist ${ }^{21}$ ). There is therefore ample opportunity for collaborative projects that encourage greater cohesion and collective learning between health professionals and built environment professionals. This will improve the quality of developments in adaptation and mitigation interventions for improving future health outcomes.

\section{Acknowledgements}

The authors gratefully acknowledge the financial and in-kind support provided by Landcom to undertake this research project.

\section{Peer review and provenance}

Externally peer reviewed, commissioned.

\section{Competing interests}

None declared. 


\section{Author contributions}

JP conceived, designed and drafted the manuscript, interpreted the data, and edited the final version of the manuscript. IC designed, drafted and edited the manuscript, and analysed and interpreted the data. EM drafted and edited the manuscript and formatted the figure. JA interpreted the data and drafted, developed and edited the manuscript. AC drafted, developed and edited the manuscript and provided analytical advice. JK designed and drafted the manuscript. CR drafted, developed and edited the manuscript and provided analytical advice. LT developed and edited the manuscript. ST developed and edited the manuscript and provided analytical advice and clarification of data. HW developed and edited the manuscript.

\section{References}

1. McMichael AJ, Neira M, Bertollini R, CampbellLendrum D, Hales S. Climate change: a time of need and opportunity for the health sector. Lancet. 2009;374(9707):2123-5.

2. Watts N, Adger WN, Agnolucci P, Blackstock J, Byass $\mathrm{P}$, Cai W, et al. Health and climate change: policy responses to protect public health. Lancet. 2015;386(10006):1861-914.

3. Bassett E, Shandas V. Innovation and climate action planning. Journal of the American Planning Association. 2010;76(4):435-50.

4. Burton A, Bambrick H, Friel S. If you don't know how can you plan? Considering the health impacts of climate change in urban planning in Australia. Urban Climate. 2015;12:104-18.

5. Thompson SM, Capon A. The co-benefits framework for understanding and action on climate change. In: Barton H, Thompson S, Burgess S, Grant M, editors. The Routledge handbook of planning for health and wellbeing: shaping a sustainable and healthy future. London: Routledge; 2015. pp. 319-32.

6. Pattanayak SK, Haines A. Implementation of policies to protect planetary health. Lancet Planet Health. 2017; 1(7):e255-6.

7. Connon ILC, Prior JH, Kent J, Thomas L, Thompson SM, Mclntyre E, et al. Healthy higher density living: a review of the literature. Sydney: Landcom; 2018.

8. Osmond P, Sharifi E. Guide to urban cooling strategies 2017. Sydney: Low Carbon Living CRC; 2017 [cited 2018 Nov 22]. Available from: www.lowcarbonlivingcrc.com.au/ sites/all/files/publications_file_attachments/rp2024_guide_ to_urban_cooling_strategies_2017_web.pdf
9. Bedsworth LW, Hanak E. Adaptation to climate change. Journal of the American Planning Association. 2010;76(4):477-95.

10. Slovic AD, de Oliveira MA, Biehl J, Ribeiro H. How can urban policies improve air quality and help mitigate global climate change: a systematic mapping review. J Urban Health. 2016;93(1):73-95.

11. Wu X, Lu Y, Zhou S, Chen L, Xu B. Impact of climate change on human infectious diseases: empirical evidence and human adaptation. Environ Int. 2016;86:1423.

12. Erwin KL. Wetlands and global climate change: the role of wetland restoration in a changing world. Wetlands Ecology and Management. 2008;17(1):71.

13. Capon AG, Synnott ES, Holliday S. Urbanism, climate change and health: systems approaches to governance. N S W Public Health Bull. 2009;20(2):24-8.

14. Raworth K. A Doughnut for the Anthropocene: humanity's compass in the 21st century. Lancet Planet Health. 2017;1(2):e48-9.

15. Kent JL, Ma L, Mulley C. The objective and perceived built environment: what matters for happiness? Cities \& Health. 2017;1(1):59-71.

16. Boyden SV. The bionarrative: the story of life and hope for the future. Canberra: ANU Press; 2016. Available from: oapen.org/search?identifier $=619468$

17. Pelling M. Adaptation to climate change: from resilience to transformation. Abingdon, Oxon: Routledge: Taylor and Francis; 2011.

18. Craig JM, Prescott SL. Planning ahead: the mental health value of natural environments. Lancet Planet Health. 2017;1(4):e128-9.

19. Berke P, Newman G, Lee J, Combs T, Kolosna C, Salvesen D. Evaluation of networks of plans and vulnerability to hazards and climate change: a resilience scorecard. Journal of the American Planning Association. 2015;81(4):287-302.

20. Lawrence R, Gatzweiler F. Wanted: a transdisciplinary knowledge domain for urban health. J Urban Health. 2017;94(4):592-6.

21. Thompson S, Kent J, Lyons C. Building partnerships for healthy environments: research, leadership and education. Health Promot J Austr. 2014;25(3):202-98.

\section{Copyright: (c)}

(c) 2018 Prior et al. This article is licensed under the Creative Commons Attribution-NonCommercial-ShareAlike 4.0 International Licence, which allows others to redistribute, adapt and share this work non-commercially provided they attribute the work and any adapted version of it is distributed under the same Creative Commons licence terms. See: www.creativecommons.org/licenses/by-nc-sa/4.0/ 